\title{
Nondestructive Evaluation of Advanced Ceramics
}

(HASA-TH-101489) NCADESTECCII BE EVALUATIOE

CF ACVANCLL CIEIEICS (NASA) I1 F CSCL 14D

\section{Uaclas \\ $63 / 38 \quad 0157264$}

Stanley J. Klima and Harold E. Kautz

Lewis Research Center

Cleveland, Ohio

Prepared for the

Twenty-sixth Automotive Technology Development

Contractor's Coordination Meeting

sponsored by the U.S. Department of Energy

Dearborn, Michigan, October 24-27, 1988

\section{Nusn}




\title{
NONDESTRUCTIVE EVALUATION OF ADVANCED CERAYICS
}

\author{
Stanley J. Klima and Harold E. Kautz \\ National Aeronautics and Space Administration \\ Lewis Research Center \\ Cleveland, Ohio 44135
}

\section{SUMMARY}

A review is presented of NASA Lewis Research Center efforts to develop nondestructive evaluation techniques for characterizing advanced cer$\sim$ amic materials. Various approaches involved the 0 use of analytical ultrasonics to characterize monolythic ceramic microstructures, acoustoultrasonics for characterizing ceramic matrix composites, damage monitoring in impact specimens by microfocus $x$-ray radiography and scanning ultrasonics, and high resolution computed $x$-ray tomography to identify structural features in fiber reinforced ceramics.

\section{INTRODUCTION}

Monolithic silicon carbide and silicon nitride are current leading candidate materials for hot section components of advanced heat engines. Although they have good average high temperature strength and excellent oxidation resistance, their brittle nature and acute sensitivity to defects leads to wide variations in mechanical properties and relatively low fracture toughness $(1,2)$. Improvements in strength and toughness can be achieved by reinforcing the monolithic materials with ceramic fibers to produce a ceramic matrix composite ( 3 ). While the strength of monolithic ceramics is generally governed by the size, population, and distribution of defects, fiber reinforced ceramics have been found to be relatively insensitive to the size of preexisting flaws in the matris (4). The strength of ceramic matrix composite $s$ is primarily dependent on fiber strength, integrity of the fibermatrix interfaces, and the ability of the matrix to distribute loads uniformly among $f$ ibers. Although the strengths of monolithic ceramics and ceramic composites appear to depend on different fabrication induced structural elements, the problems of poor reliability and reproducibility are common to both classes of material.
One approach to improved reliability and reproducibility of ceramics is to utilize nondestructive evaluation ( VDE) techniques during materials research and development to help identify when harmful flaws are introduced. Steps can then be taken to minimize their occurrence through improvements in processing. Another approach is to use NDE as a materials characterization tool to provide indirect assurance that components exhibit correct microstructures and uniform properties. This can be done at various stages of processing to save the cost of finishing parts deemed to be defective at an early stage. The least efficient approach, although often unavoidable, is to use VDE after the last stage of faorication to eliminate parts that contain harmful flaws. No matter when NDE is applied, effective utilization requires close control over the procedures used to make the nondestructive measurements and careful interpretation of the data to assure meaningful conclusions.

This report describes the capabilities and limitations of several ultrasonic techniques for characterizing monolithic and composite ceramics and the conditions under which they can be applied effectively. Also described is a preliminary effort to perform damage monitoring in impact specimens, and results of initial studies of high resolution computed tomography for evaluation of ceramic composites.

\section{ANALYTICAL ULTRASONICS}

Ultrasonic methodology for determining microstructure and mechanical properties of ceramic materials is of high interest. Empirical relationships between ultrasonic velocity, attenuation, bulk density, grain size, and strength properties have been observed $(5-7)$ and conceptual models for explaining and predicting empirical correlations have been advanced ( 8 ). Accurate determination of these empirical relationships depends to a large degree on the experimental technique used to measure not only the material 
properties but on the technique used to make the ultrasonic measurements (9). It has been shown, for example, that inaccuracies in attenuation measurements made with broadband ultrasonic pulses can result unless the frequency dependence of the reflection coefficient is incorporated in the signal analysis (10). In the following paragraphs the effects of specimen surface finish, pore fraction, pore size and shape, and grain size on ultrasonic velocity and attenuation measurements will be discussed.

EFFECT OF SURFACE FINISH - Figure 1 iliustrates the effect of surface roughness on the ultrasonic reflection coefficient, a property that influences the measurement of ultrasonic attenuation. The reflection coefficient gives the proportion of incident energy reflected at an interface. In this case the interface is composed of a quartz buffer in contact with a silicon carbide specimen and a liquid couplant (glycerine) filling the gaps. The experimental data for all four curves in Fig. I were taken using same transducer-sample pair, but with four different sample surface preparations (6). It is evident that the reflection coefficient increased when surface roughness exceeded $1 \mu \mathrm{m}$ peak-to-valley height $\left(R_{y}\right)$. This is because higher $R_{y}$ values created thicker interfacial layers, making transmission more difficult. Note that in all cases the experimentally determined reflection coefficient increased with increasing ultrasonic frequency. This is expected since shorter wavelengths are more readily scattered and reflected at an interface. For reference purposes the theoretical reflection coefficient, a function of the densities and velocities of the mating materials, was calculated assuming zero interface thickness and no couplant, making frequency effects negligible.

Figure 2 shows the effect of surface roughness on ultrasonic attenuation coefficient measured on the same silicon carbide sample.

Although the effect of increasing roughness on attenuation does not appear to be as dramatic as the effect on reflection coefficient, the same trend is evident. For $R_{y}$ of 0.6 and $1.0 \mu \mathrm{m}$ the measured attenuation appears to be equivalent, but is shown to increase for higher peakto-valley heights. For example, the attenuation coefficient at $100 \mathrm{MHz}$ increased by a factor of two for $R_{y}$ of $3.0 \mu m$ over that measured for $R_{y}$ of $1.0 \mu \mathrm{m}$. It must be concluded that when accurate attenuation measurements are needed, the surface roughness should not exceed peak-tovalley heights of $1 \mu \mathrm{m}$. Nevertheless, it should be possible to make comparative attenuation measurements on specimens with rougher surfaces as long as the surface finish is the same on all samples.

EFFECT OF DENSITY, PORE SIZE, AND GRAIN SIZE ON ATTENUATION - The effect of bulk density, pore size, and grain size on attenuation of specially prepared silicon carbide specimens is shown in Fig. 3. Three batches of material were sintered under different conditions to produce samples with varying bulk density and mean pore size with corresponding variations in grain size (6). Each batch contained at least eight specimens. The attenuation as a function of frequency was measured for all specimens but, for simplicity, only the scatter band for each batch is plotted. The width of the scatter bands indicate that significant variations exist within batches. It should be noted that valid comparisons at ultrasonic frequencies below $60 \mathrm{MHz}$ were not possible because, at these longer wavelengths, the attenuation could not be distinguished from zero except for samples with densities less than about 95 percent of theoretical. Low ultrasonic attenuation is characteristic of nearly fully dense structural ceramics with fine microstructures. Thus, siznificant attenuation differences between batches are evident only in the frequency range above approximately $100 \mathrm{MHz}$ where the ultrasonic wavelength is less than 10 to 20 times the average grain size and pore size.

The data in Fig. 3 show that the magnitude of ultrasonic attenuation is influenced by bulk density and what appears to be a combined effect of pore size and grain size. For example, even though the average bulk densities of batch 1 and batch 2 are equivalent, the attenuation of batch 2 is higher, apparently because the mean pore size and grain size are significantly greater. On the other hand, although the mean pore sizes and grain sizes of batch 2 and 3 are nearly the same, the attenuation of batch 3 is higher, probably because the density is lower. Unfortunately, the sintering parameters utilized did not permit variation of grain size independently of pore size and so the independent effects of these. two microstructural variables could not be determined. However, when measurements are made at the appropriate frequencies, ultrasonic attenuation can be a very sensitive indicator of overall variations in microstructure of structural ceramics. Furthermore, if other variables such as grain size and pore size are closely controlled, the technique can be useful for measuring a specific property such as bulk density.

RELATIONSHIP BETWEEN ULTRASONIC VELOCITY AND

DENSITY - Figure 4 shows that a relation exists between ultrasonic velocity and bulk density for four batches of silicon carbide, each with a different mean pore size and grain size (6). It is evident that velocity is a steadily increasing function of density, and that the variations in pore size and grain size have little effect on this correlation. For example, the data for two batches of material with average densities of about $\left(3.11 \mathrm{~g} / \mathrm{cm}^{3}\right)$ show only a slight velocity difference, in spite of the fact that the pore sizes and grain sizes for the two batches differ by a factor of two. The data for the other two batches appear to be affected primarily by material bulk density and, again, very little by the wide differences in pore and grain size. This observation agrees with that made previously in Ref. 5 which concluded that ultrasonic velocity could be used to measure bulk density of silicon carbide to within 1 percent, given that a suitable calibration is available. If grain size is a closely controlled parameter, measurement of density within a fraction of a percent should be 
possible. Even in lieu of calibration curves, the use of ultrasonic velocity is a viable quality control option for qualitative ranking of specimens of a given material on the basis of material density.

\section{ACOUSTO-ULTRASONICS}

Analysis of ultrasonic signals recovered Erom composites by conventional methods is often impossible because the heterogeneous structure of the laminate creates a tortuous path for sound waves, resulting in multimodal transmission and superposition of multiple signals arriving at the receiver at about the same time. The result is a complex "noisy" waveform that is difficult to interpret. A new technique termed acoustoultrasonics has emerged (11) which offers a unique way of evaluating composite panels by measuring bulk material effects on ultrasonic transmission rather than detecting discrete defects. A block diagram in Fig. 5 illustrates the technique. A sending transducer creates sound waves in the panel specimen and a receiving transducer detects the transmitted waves on the same surface. The received waveform is digitized for further analysis. A sample waveform from a silicon nitride specimen reinforced with silicon carbide fibers is presented in Fig. 6. It is clear that the time domain signal (Fig. 6(a)) is irregular and has a long ringdown time, typical of a waveform comprised of multiple signals arriving together. By performing a Fourier transform, the frequency spectra of the received signal is obtained

(Fig. 6(b)). At least four distinct frequency peaks are evident, further illustrating the complexity of the signal. From the frequency spectra a quantity termed the "stress-wave factor" can be obtained by determining the area beneath the entire curve or any part of the curve, for example the area beneath one of the peaks. A detailed description of acousto-ultrasonic wave paths, signal analysis, and their relationship to material properties of composite materials can be found in Ref. 12.

Stress-wave factor measurements were made on $\mathrm{SiC}_{\mathrm{F}} / \mathrm{Si}_{3} \mathrm{~N}_{4}$ tensile specimens exposed to an oxidizing environment at temperatures ranging from 700 to $1200^{\circ} \mathrm{C}$. The data presented in Fig. 7 show that an empirical relationship exists between normalized stress-wave factor and elastic modulus measured in tension. The relationship suggests that the stress-wave factor may be sensitive to a number of factors that contribute to the stiffness of the material, including the integrity of the interfacial bond between fibers and matrix. Thus, acousto-ultrasonic measurements may be useful for estimating the overall quality of composite materials.

\section{DAMAGE MONITORING}

There is increasing interest in utilizing nondestructive examination procedures for monitoring damage accumulation in test specimens of advanced ceramic materials to help identify failure modes. Although fractographic analys is is an extremely useful technique for determining fracture origins in monolythic ceramics after failure, it has limited applicability to fiber reinforced composites because these materials are less sensitive to discrete defects. Widely varying matrix densities, bridging, and load redistribution by the fibers tend to create multiple crack sites, making identification of an initial crack impossible. It appears that damage monitoring in ceramic matrix composites may be more informative when performed on a global scale to follow general trends in the failure process. Thus, an initial attempt was made at utilizing radiography and ultrasonics to map the damage zones in high velocity pellet impact test specimens.

A photograph of the impacted surface of a $\mathrm{SiC}_{\mathrm{F}} / \mathrm{Si}_{3} \mathrm{~N}_{4}$ test coupon is shown in Fig. 8 . Apparent impact damage is indicated by a small circular spalled zone in center of the specimen. The surface spalling along the bottom edge of the specimen existed prior to testing and was unchanged. No damage of any kind was evident on the back side of the sample. Figure 9 shows radiographs of the same sample taken before and after testing. The radiograph taken before testing shows that internal matrix cracking existed before the specimen was impacted and that these were probably fabrication flaws. Had the specimen not been $x$-rayed, the cracks upon later observation may have been assumed to be caused by the high velocity pellet impact. The radiograph taken after testing gives no indication that the pre-existing cracks were enlarged by the impact, nor does it suggest that there was any interaction between these cracks and the spalling caused by the pellet. Figure 10 shows an ultrasonic C-scan of the same specimen made after impact testing. This image shows that impact damage is more extensive than indicated by the radiograph. The damaged area indicated by the ultrasonic C-scan is about 16 percent of the total specimen area, compared to less than 1 percent indicated by the radiograph (Fig. $9(b)$ ) which is about the same as would be estimated from the photograph of the specimen surface (Fig. 8). The fact that the $x$-rays missed a major part of the damage suggests that it is probably delamination in the plane of the specimen. Cracking that occurs in this plane is transparent to $x$-rays (in the absence of spal1ing) but is favorably oriented for detection by ultrasonic waves because it acts as a reflector. Thus, the need for evaluation of specimens by NDE techniques that complement one another is evident.

\section{COMPUTED TOMOGRAPHY}

Computed $x$-ray tomography (CT) has been used in medical applications for nearly two decades and in large industrial applications for nearly a decade. The first industrial systems were developed for inspection of fully loaded, large diameter rocket motors measuring from 1 to $2.4 \mathrm{~m}$ in diameter (13). Neither the medical units nor the early industrial systems were designed to produce the high resolution images required for material characterization. Only in the last 3 years has 
attention been focused on the need for nondestructively examining specimens and components for mapping and sizing of small (less than $250 \mu \mathrm{m}$ ) internal flaws and for characterizing internal structure by tomographic methods. An example of preliminary results is shown in Fig. 11. The image is a CT slice through a cross section of a small $\mathrm{SiC}_{F} / \mathrm{Si}_{3} \mathrm{~N}_{4}$ composite sample. The silicon carbide fibers, $140 \mu \mathrm{m}$ in diameter, are differentiated from the silicon nitride matrix. Though it may not be obvious from the image in Fig. 11, matrix density variations can be seen on a monitor and in the original photographs. The theoretical densities of the fibers and matrix are similar but the actual density of the matrix is only 60 percent of theoretical which makes imaging of the fibers easier. The center of the $f i b-$ ers is composed of a carbon core which is only $25 \mu \mathrm{m}$ diameter and is seen as a dark spot in the middle of the fiber. It is evident that although these relatively small features (fiber and core) are nicely imaged, they cannot be dimensioned accurately because the resolution of the system used is approximately 25 to $35 \mu \mathrm{m}$. Nevertheless, the results represent a factor of 5 to 10 improvement in resolution over previous industrial CT systems.

\section{CONCLUSION}

Ultrasonic attenuation in monolythic ceramics was strongly affected by bulk density, grain size, and pore size. The accuracy of attenuation measurements was found to be sensitive to specimen surface roughness, requiring a surface with maximum peak-to-valley height of $1 \mu \mathrm{m}$. Although less sensitive than attenuation, ultrasonic velocity was more attractive for estimating bulk density because measurements were not strongly affected by surface finish and pore size/grain size considerations.

Preliminary results with acousto-ultrasonics indicate that the technique may be useful as an indicator of composite material quality. A relationship was demonstrated between a quantity referred to as the stress-wave factor and elastic modulus of silicon carbide fiber reinforced silicon nitride specimens.

Microfocus radiography and scanning ultrasonics were used together to successfully map pre-existing flaws, and damage incurred by high velocity pellet impact tests on fiber reinforced silicon nitride. Radiographs revealed internal fabrication induced matrix cracks while ultrasonics gave a more accurate measure of apparent delaminations caused by impacting.

Initial studies with a recently developed high resolution computed $\mathrm{x}$-ray tomography system applied to ceramic composites showed that 25 to $35 \mu \mathrm{m}$ resolution is attainable. Cross sections of $140 \mu \mathrm{m}$ silicon carbide fibers with $25 \mu \mathrm{m}$ carbon cores imbedded in a silicon nitride matrix were differentiated from each other.

\section{REFERENCES}

1. D.R. Johnson, et al., "Ceramic Technology for Advanced Heat Engines Project," American Ceramic Society Bulletin, Vol. 64, No. 2, Feb. 1985, pp. 276-281.

2. R.T. Bubsey, J.L. Shannon, Jr., and D. Munz, "Development of Plane Strain Fracture Toughness Test for Ceramics Using Chevron Notched Specimens," Ceramics for High-Performance Applications III: Reliability, E.M. Lenoe, R.N. Katz, and J.J. Burke, eds., Plenum Press, 1983, pp. 753-771.

3. R.T. Bhatt, "Effects of Fabrication Conditions on the Properties of SiC Fiber Reinforced Reaction-Bonded Silicon Vitride Matrix Composites (SiC/RBSN)," NASA TM-88814, 1986.

4. D.3. Marsha11, "NDE of Fiber and WhiskerReinforced Ceramics," Review of Progress in Quantitative Nondestuctive Evaluation, Vo1. 6A, D.0. Thompson and D.E. Chimmenti, eds., P1enum Press, 1986, pp. 60-69.

5. S.J. Klima, G.K. Watson, T.P. Herbell, and T.J. Moore, "Ultrasonic Velocity for Estimating Density of Structural Ceramics," NASA TM-82765, DOE/NASA/51040-35, 1981.

6. G.Y. Baaklini, E.R. Generazio, and J.D. Kiser, "High Frequency Ultrasonic Characterization of Sintered SiC," NASA TiY-100825, 1987.

7. A. Vary, and D.R. Hull, "Ultrasonic Ranking of Toughness of Tungsten Carbide," NASA TM-83358, 1983.

8. A. Vary, "Concepts for Interrelating U1trasonic Attenuation, Microstructure, and Fracture Toughness in Polycrystalline Solids, Materials Evaluation, Vol. 46, No. 5, Apr. 1988, pp. 642-649.

9. E.P. Papadakis, K.A. Fowler, and L.C. Lynnworth, "U1trasonic Attenuation by Spectrum Analysis of Pulses in Buffer Rods: Method and Diffraction Corrections," Journal of the Acoustical Society of America, Vol. 53, No. 5, May 1973, pp. 1336-1343.

10. E.R. Generazio, "The Role of the Reflection Coefficient in Precision Measurement of Ultrasonic Attenuation," Materials Evaluation, Vol. 43, No. 7, July 1985, pp. 995-1004 (NASA TM-83788).

11. A. Vary, and K.J. Bowles, "Ultrasonic Evaluation of The Strength of Unidirectional Graphite-Polymide Composites," NASA TM X-73646, 1977. 
12. H.E. Kautz, "Ray Propagation Path Analys is of Acousto-Ultrasonic Signals in Composites," Acousto-Ultrasonics, Theory and Application, Plenum Press, 1988, PP. 127-142 (NASA

TM-100148).
13. R.A. Armistead, "CT: Quantitative 3-D Inspection," Advanced Materials \& Processes, Vol. 133, No. 3, March 1988, pp. 42-48.

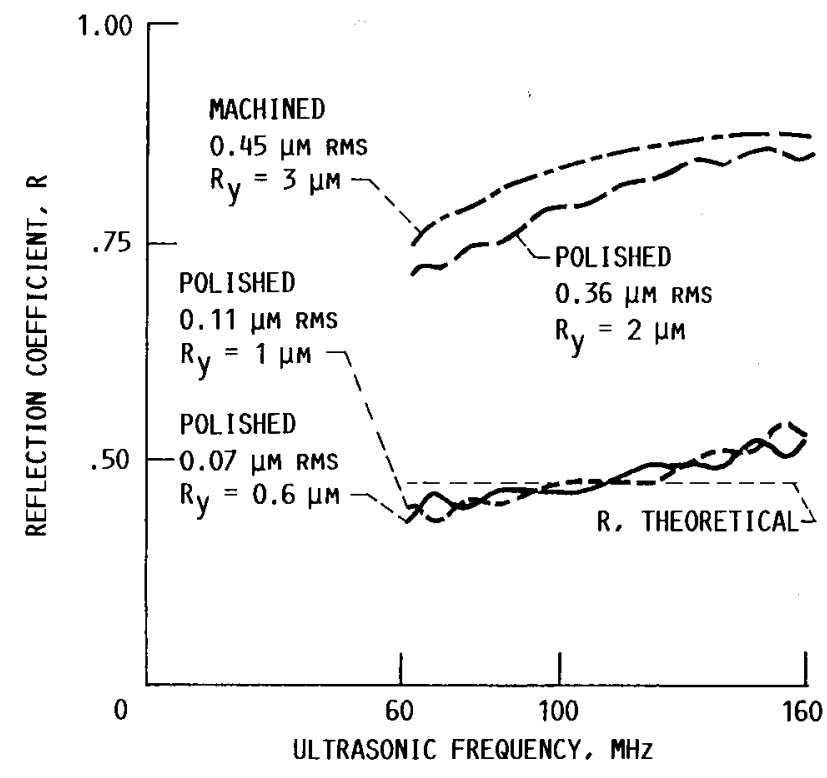

FIGURE 1. - EFFECT OF SURFACE ROUGHNESS ON ULTRASONIC REFLECTION COEFFICIENT AT A QUARTZ-SIC INTERFACE. Ry IS THE MAXIMUM PEAK-TO-VALLEY HEIGHT OF SPECIMEN SURFACE IRREGULARITIES. THE THEORETICAL $R$ WAS CALCULATED FROM ACOUSTIC IMPEDANCES OF QUARTZ AND SIC. (FROM REF. 6).

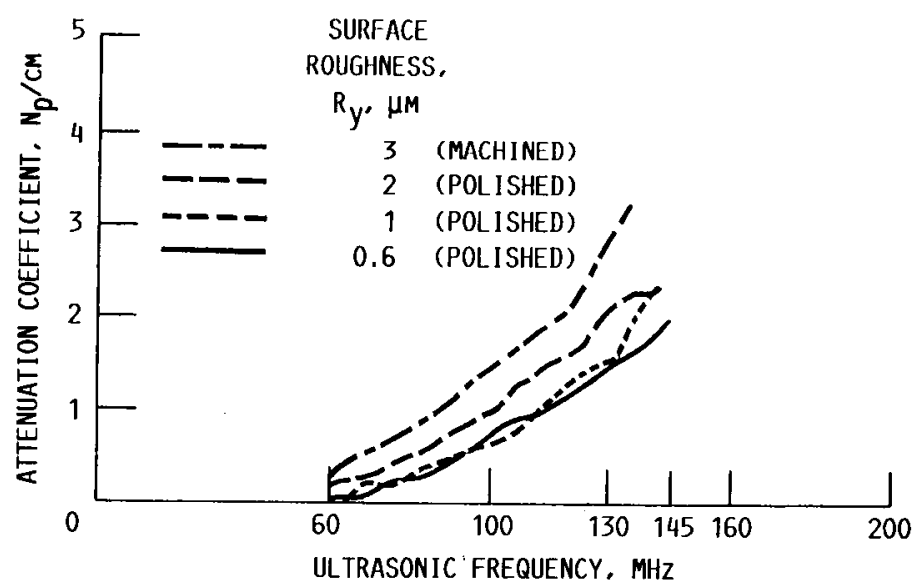

FIGURE 2. - EFFECT OF SURFACE ROUGHNESS ON ULTRASONIC ATTENUATION COEFFICIENT MEASURED ON A SINGLE SAMPLE OF SINTERED SIC. MAXIMUM PEAK-TO-VALLEY HEIGHT, $R_{Y}$. OF THE SPECIMEN WAS VARIED BY GRINDING OR POLISHING. (FROM REF, 6). 


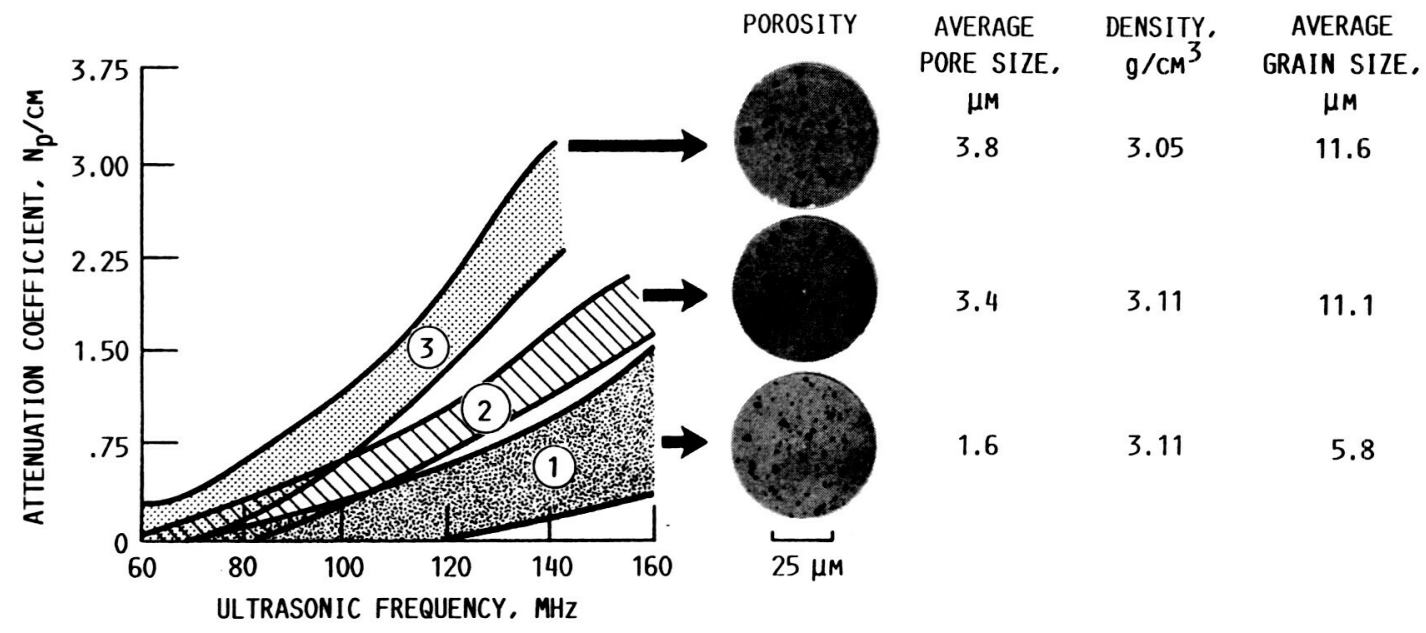

FIGURE 3. - DATA FOR SINTERED SIC SHOWING THAT ULTRASONIC ATTENUATION IS INFLUENCED BY BULK DENSITY AND BY AVERAGE PORE/GRAIN SIZE. (FROM REF. 6).

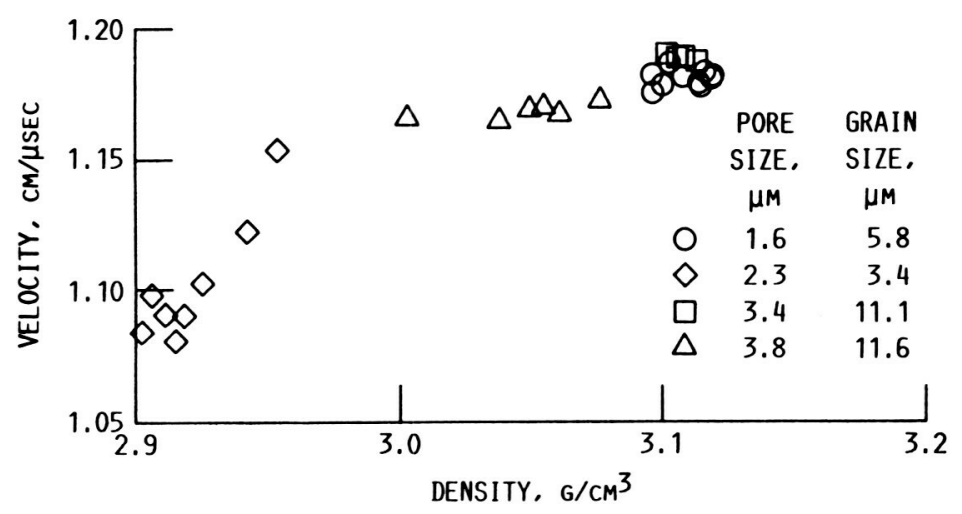

FIGURE 4. - DATA FOR SINTERED SIC SHOWING THAT ULTRASONIC VELOCITY IS GOVERNED PRIMARILY BY BULK DENSITY AND RELATIVELY UNAFFECTED BY DIFFERENCES IN GRAIN SIZE AND PORE SIZE. (FROM REF. 6). 


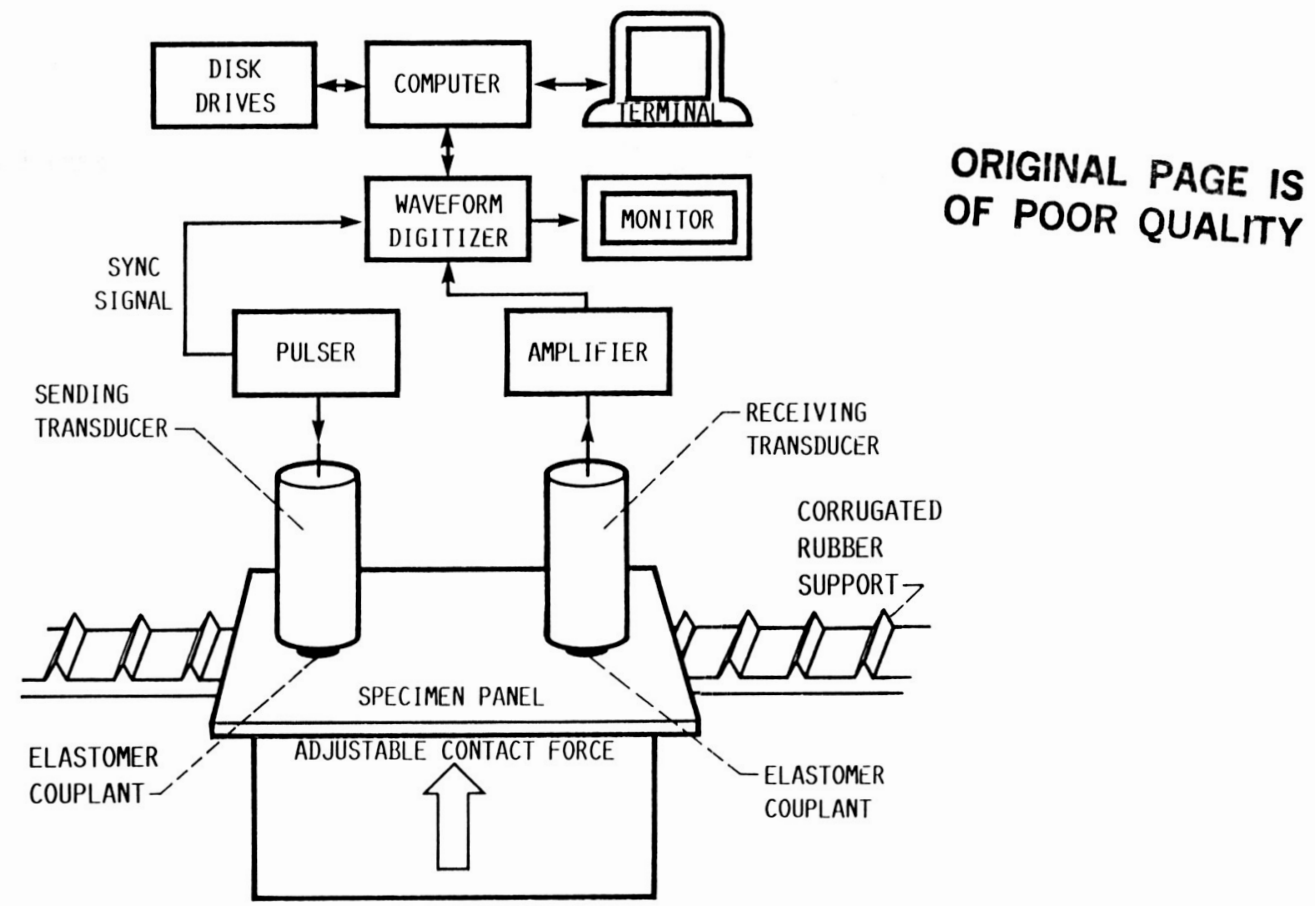

FIGURE 5. - SCHEMATIC DIAGRAM OF AN ACOUSTO-ULTRASONIC SYSTEM.

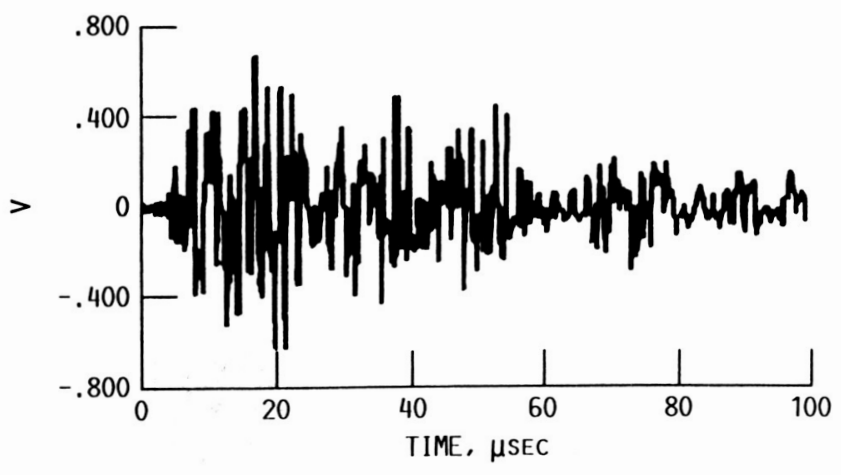

(A) TIME DOMAIN SIGNAL.

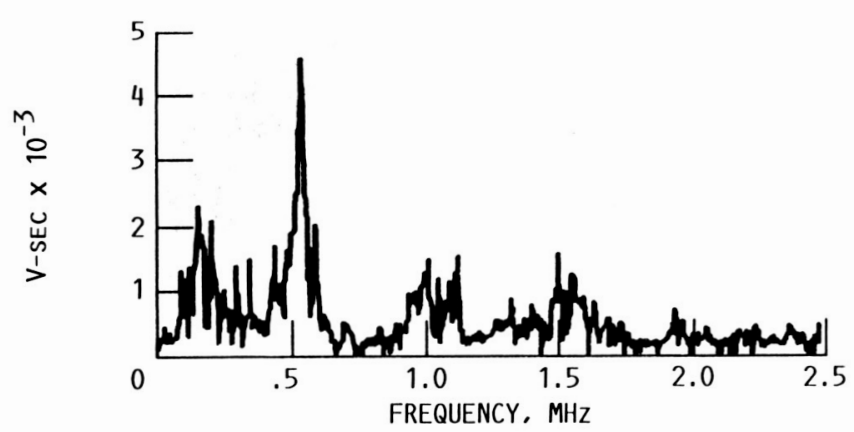

(B) FREQUENCY DOMAIN SIGNAL.

FIGURE 6. - ACOUSTO-ULTRASONIC WAVEFORM FROM A SILICON NITRIDE SPECIMEN REINFORCED WITH SILICON CARBIDE FIBERS.

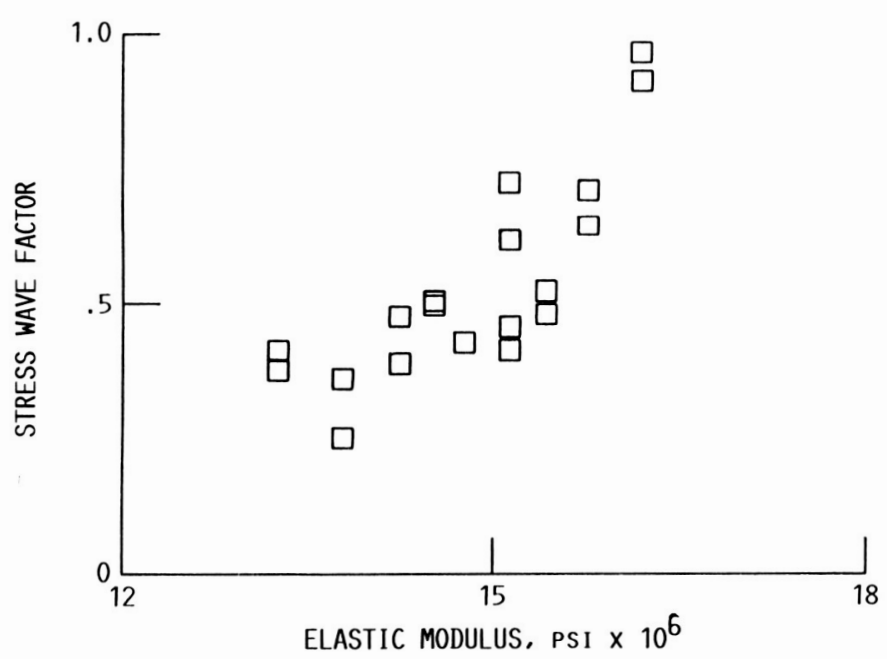

FIGURE 7. - RELATIONSHIP BETWEEN NORMAL IZED STRESSWAVE FACTOR AND ELASTIC MODULUS OF SILICON NITRIDE REINFORCED WITH SILICON CARBIDE FIBERS, SPECIMENS WERE HEATED 10 HOURS IN $0_{2}$ AT TEMPERATURES FROM $700{ }^{\circ} \mathrm{C}$ TO $1200{ }^{\circ} \mathrm{C}$. EACH DATA POINT REPRESENTS ONE TENSILE SPECIMEN. 


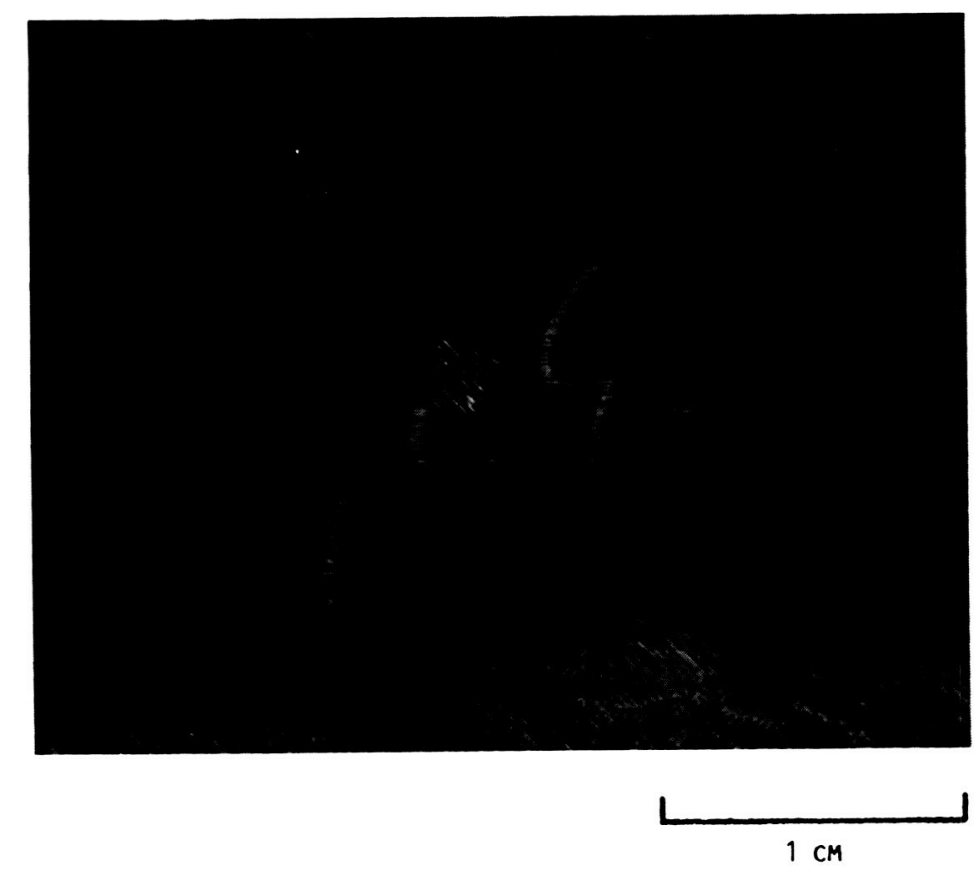

FIGURE 8. - PHOTOGRAPH OF $\mathrm{SIC}_{\mathrm{F}} / \mathrm{Si}_{3} \mathrm{~N}_{4}$ TEST COUPON IMPACTED BY $6.3 \mathrm{mM}$ STEEL BALL AT $20 \mathrm{~m} / \mathrm{s}$. LITTLE APPARENT DAMAGE OUTSIDE POINT OF IMPACT IN CENTER. BOTTOM EDGE WAS SPALLED BEFORE TESTING.

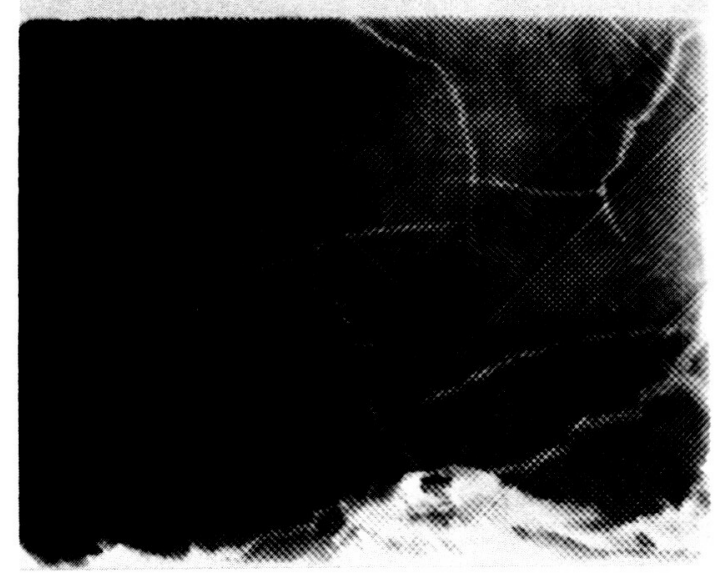

(A) BEFORE TESTING.

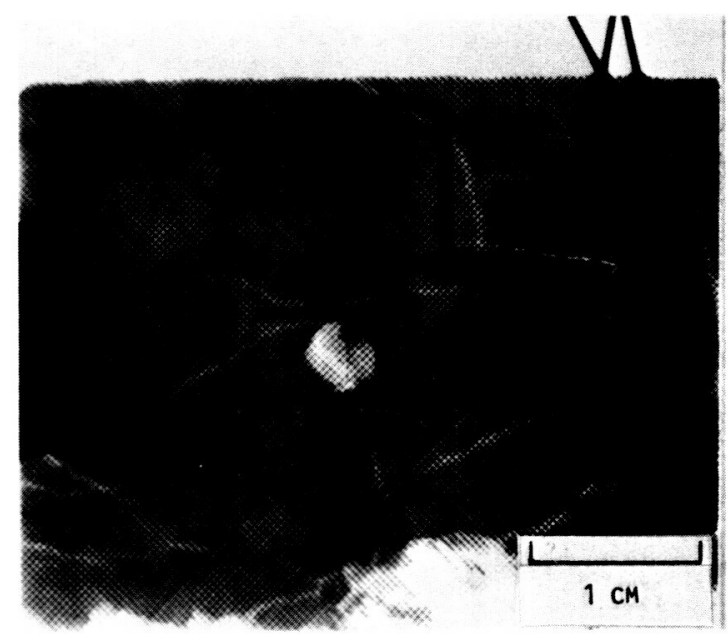

(B) AFTER TESTING.

FIGURE 9. - X-RAY RADIGRAPHS OF $\mathrm{SIC}_{\mathrm{F}} / \mathrm{Si}_{3} \mathrm{~N}_{4}$ TEST COUPON BEFORE AND AFTER IMPACT TESTING. WHITE LINES INDICATE THE MATRIX WAS CRACKED PRIOR TO TESTING. DAMAGE APPEARS CONFINED TO THE POINT OF IMPACT. PRE-EXISTING CRACKS DID NOT GROW SIGNIFICANTLY. ALSO SHOWN ARE STRAIN GAGES ATTACHED TO THE BACKSIDE OF THE.SPECIMEN TO MEASURE DEFLECTION. 


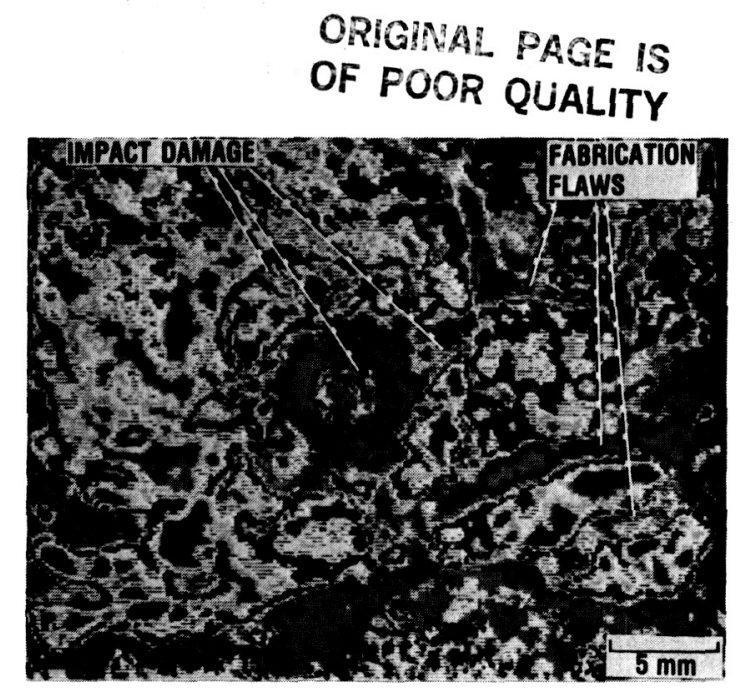

FIGURE 10. - ULTRASONIC C-SCAN OF $\mathrm{SiC}_{\mathrm{F}} / \mathrm{Si}_{3} \mathrm{~N}_{4}$ TEST COUPON AFTER IMPACT TESTING. IMAGE WAS MADE BY RECORDING THE AMPLITUDE OF THE BACKWALL ECHO.

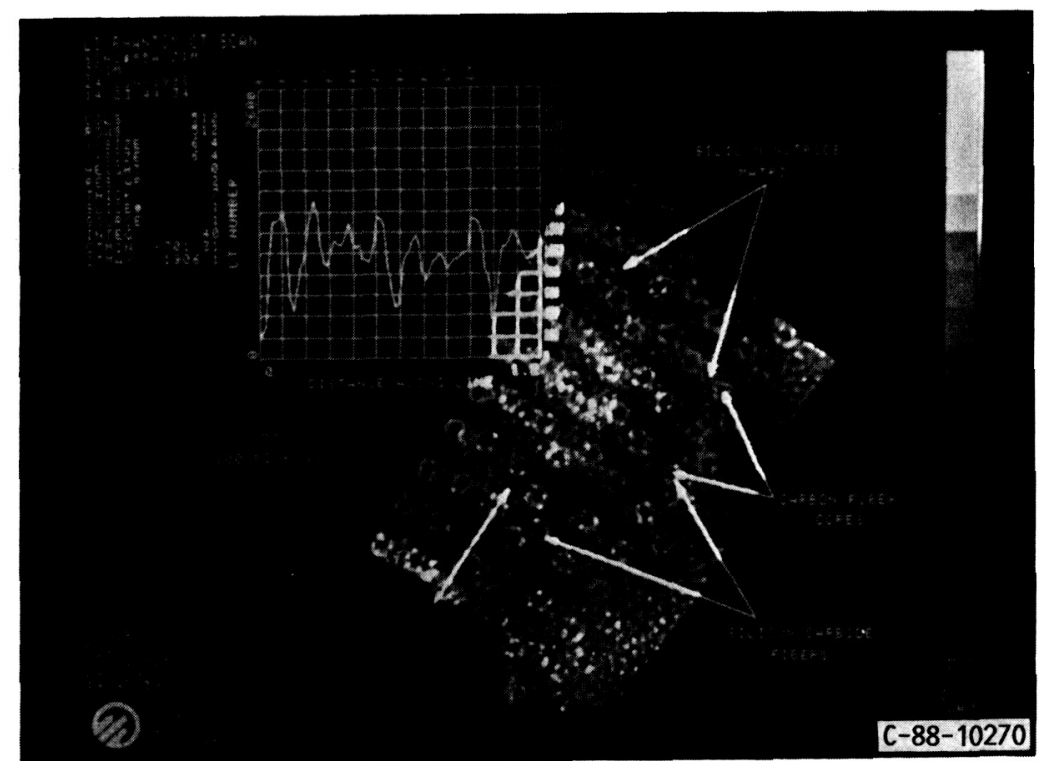

FIGURE 11. - HIGH RESOLUTION COMPUTED TOMOGRAPHY IMAGE OF A CERAMIC MATRIX COMPOSITE. $140 \mu \mathrm{M}$ DIAMETER SIC FIBERS ARE DIFFERENTIATED FROM THE $\mathrm{Si}_{3} \mathrm{~N}_{4}$ MATRIX WHICH AVERAGES 60 PERCENT OF THEORETICAL DENSITY. $25 \mu \mathrm{M}$ CARBON CORES ARE CLEARLY IMAGED. (CT SCAN BY ARACOR). 


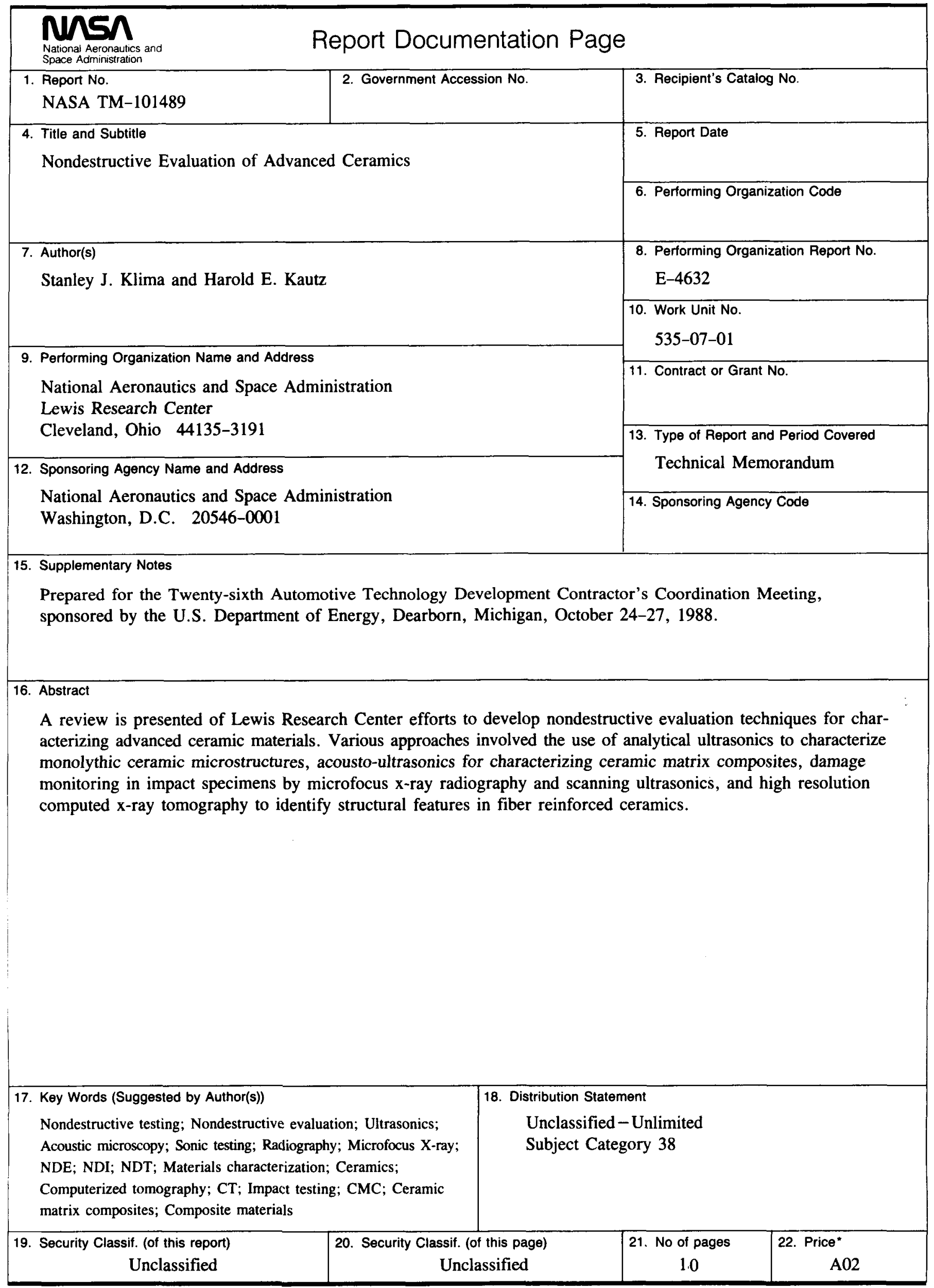

